\author{
Marcin GOLASZEWSKI ${ }^{1}$ \\ Marcin KROLIKOWSKI ${ }^{1}$ \\ Bartosz POWALKA ${ }^{1}$
}

\title{
PARALLEL CROSS-SECTION RECOGNITION OF GEOMETRICAL FEATURES FOR SELECTED MACHINE PARTS
}

\begin{abstract}
Increase of automation and autonomy of production is the latest trend incorporated into Industry 4.0 objectives. Production autonomy is very desirable in the field of damaged parts replacement. To fulfill this goal numerous reverse engineering systems have been developed that support geometry recognition from the 3D scan data. This study is focused on converting non-parametric geometry representation of shaft-type elements into a CAD model with a rebuilt feature tree. Algorithms are based on the analysis of parallel cross-sections. The proposed system is also capable of identification of additional geometric features typical for 2.5 axes milling such as pockets, islands and outer walls. The proposed algorithms are optimized to increase efficiency of the process. Initial identification parameters are selected with respect to defined criteria, e.g., identification accuracy, computing power and scanning accuracy. Described algorithms can be implemented in reverse engineering systems.
\end{abstract}

\section{INTRODUCTION}

According to the idea of Industry 4.0, every process or physical object should have a digital twin. The digital twin is the digital representation that accompanies a product throughout its life cycle $[1,2]$. The digital twin can be not only a 3D model, but also a feature tree of the model, allowing to plan the manufacturing technology. However, a digital equivalent of the object is not always available. In such a situation, a digital equivalent must be created. Pattern recognition algorithms are used to create a digital environment of both the technological process and the physical object $[3,4]$.

Two trends in the use of pattern recognition algorithms are present in mechanical engineering. The first is used in Computer-Aided Process Planning (CAPP) systems. These systems provide a link between Computer Aided Design (CAD) and Computer Aided Manufacturing (CAM) systems. The role of feature recognition systems in CAPP programs boils down to the classification of features in order to automatically determine their

\footnotetext{
${ }^{1}$ Faculty of Mechanical Engineering and Mechatronics, West Pomeranian University of Technology, Poland

*E-mail: marcin.golaszewski@zut.edu.pl https://doi.org/10.36897/jme/141500
} 
manufacturing technology [5]. One way of feature recognition in CAPP systems is Graph Pattern Analysis (GPA). This approach was presented by JungHyun Han, Mike Pratt and William C. Regli [6]. In addition, attempts have been made to implement neural networks into GPA systems. This was done by researchers at the Indian Institute of Technology in Bombay [7]. The GPA method assumes an analysis of the model wall connections, for which a parametric geometry in Boundary-Representation (B-rep) is required. The GPA method can also be used to reconstruct the B-rep geometry from Constructive Solid Geometry (CSG) [8].

The second strand is the use of feature recognition tools in Computer Aided Reengineering (CAR) systems [9]. The task of these systems is to create parametric geometry from a point cloud. One approach in this strand is the use of 3D neural networks. For this purpose, a 3D matrix is applied to the 3D model [10, 11]. Zhibo Zhang, Prakhar Jaiswal and Rahul Rai presented the use of this method in CAPP programs [12], but the method can also be adapted in CAR systems. The problem with this method is to choose the right resolution of the matrix so that the features are recognized correctly. A completely different approach is the feature recognition method using sectional view representation [13]. This method allows the use of 2D neural networks but, like the GPA method, it is used more often in CAPP programs. The use of the projection method for applications in CAR systems was presented by researchers from Samara National Research University [14]. Authors at first have created projection images of the geometry, then neural network has been used for image segmentation [15]. After segmentation, pixels have been compared to the coordinates of the corresponding projection in order to match pixels to recognized faces. This approach allows the reconstruction of a surface model based on point cloud projections onto coordinates planes. The advantage of this approach is that 2D convolutional neural networks can be used.

This paper presents a method for identifying the structural features of shaft class parts based on cross-sections. The method presented allows the identification of structural features (implementation in CAPP systems) and the reconstruction of parametric B-rep geometry (implementation in CAR systems) from a point cloud. The method described uses a 2D convolutional neural network for regression and a $2 \mathrm{D}$ convolutional neural network for identification, which reduces computation time relative to $3 \mathrm{D}$ networks.

Furthermore, the method allows the identification of more complex features than the method using sectional view representation. Unlike the GPA method, no parametric geometry format is required.

\section{METHOD}

Chapter 2 describes the method of identification and reconstruction of parametric geometry. It first describes how the data was obtained. It then describes how to determine the cross-sectional planes and proposes how to select the resolution of the matrix. Next, a method for orienting cross sections using a 2D convolutional neural network for regression is presented. Section 2.4 describes how to teach an appropriate neural network for identification. The following section describes how to determine the dimensions of the identified features and how to group cross-sections into structural features. It then shows how to determine the axis of the shaft and how to rebuild the geometry with the reconstruction of the operation tree. 


\subsection{SCANNING}

In order to obtain data for learning the neural network and validating the system, 8 shafts were modelled and manufactured using additive manufacturing techniques. The shafts were modelled in a way to distinguish 5 different types of step geometries: gear (Fig. 1a), spline (Fig. 1b), groove (Fig. 1c), straight step (with circular cross-section) (Fig. 1d) and milled step (Fig. 1e). A shaft having all classes of cross-sections (Fig. 2a) was used to test the system and verify the method of identifying geometrical features. The cross sections extracted from the 7 shafts were used to teach, validate and test the neural networks (Fig. 2b-2h). The fabricated and scanned shafts with marked geometrical features are shown in Fig. 2.

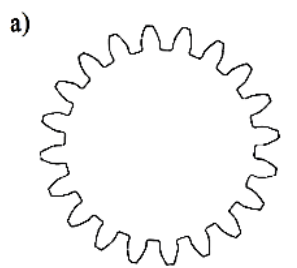

b)

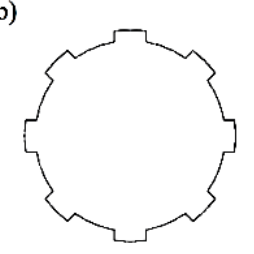

c)

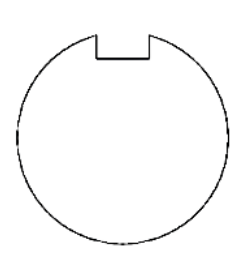

d)

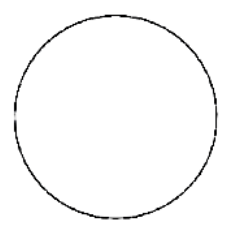

e)

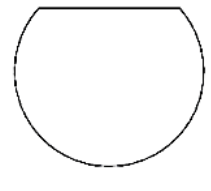

Fig. 1. Types of identified geometry of parts of the shaft class

a)

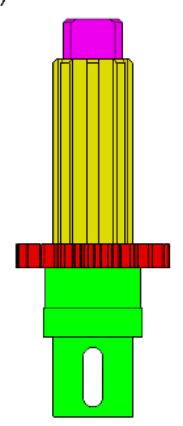

e)

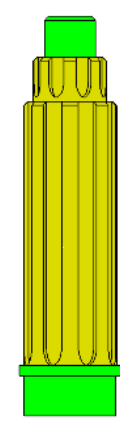

b)

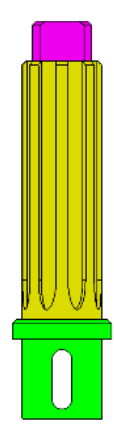

f)

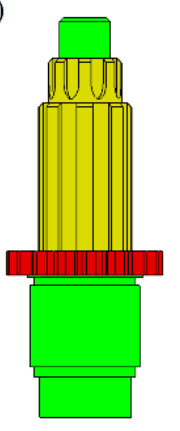

c)

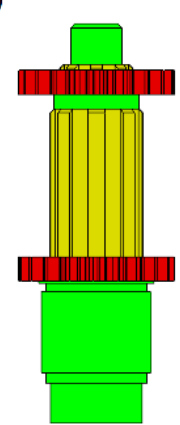

g)

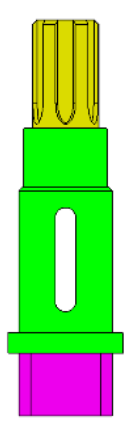

d)

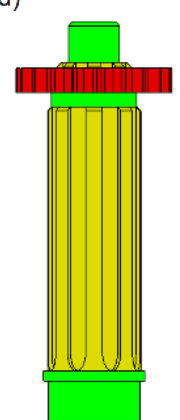

h)

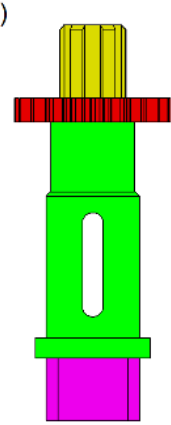

Fig .2. Manufactured shafts

The shafts were scanned using an Artec Eva Lite scanner with single point scanning accuracy of $0.1 \mathrm{~mm}$ and surface scanning accuracy of $0.5 \mathrm{~mm}$ [16]. The files were converted into the point cloud format. In reverse engineering, only the physical object is available, as 
the CAD model does not exist or inaccessible [17]. In the case described here, the CAD model of the reference geometry is only used for analysis and qualitative evaluation of the scan $[18,19]$.

Note that the teeth of the gear have been angularly displaced in the shaft axis during the scanning process, as can be seen in Fig. 3a. The maximum value of deviation is $4.38 \mathrm{~mm}$. The overall quality of the scan was determined by the median and standard deviation values. The median and standard deviation values are summarized in Table 1. The distribution of total deviation is shown in Fig. 3a and the distribution histogram of deviation in Fig. $3 b$.

a)

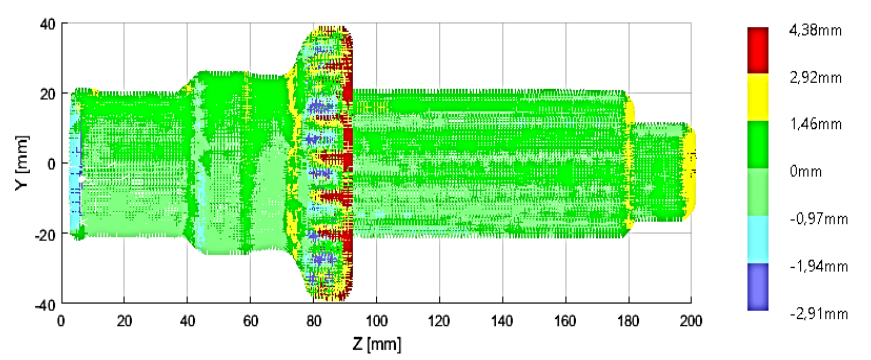

b)

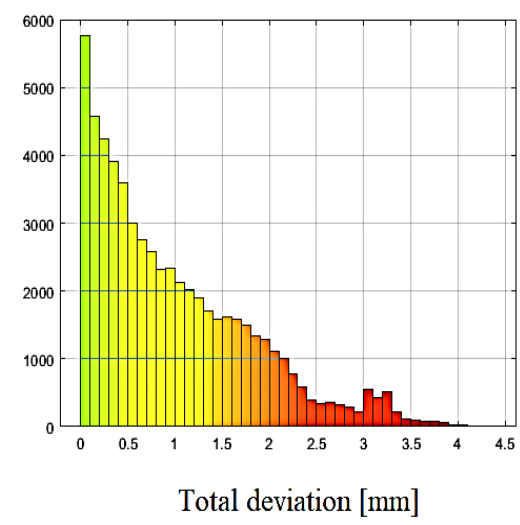

Fig. 3. a) Values of deviation of comparison scan with reference geometry; b) Distribution histogram

Table 1 Standard deviation and median value of deviation

\begin{tabular}{|c|c|c|c|}
\hline $\begin{array}{c}\text { Standard } \\
\text { deviation } \\
\text { X-axis }\end{array}$ & $\begin{array}{c}\text { Standard } \\
\text { deviation } \\
\text { Y-axis }\end{array}$ & $\begin{array}{c}\text { Standard } \\
\text { deviation } \\
\text { Z-axis }\end{array}$ & $\begin{array}{c}\text { Total } \\
\text { Standard } \\
\text { deviation }\end{array}$ \\
\hline 0.61 & 0.63 & 0.96 & 0.84 \\
\hline $\begin{array}{c}\text { Median } \\
\text { X-axis }\end{array}$ & $\begin{array}{c}\text { Median } \\
\text { Y-axis } \\
\text { Deviation* } \\
\text { Deviation* } \\
\text { [mm] }\end{array}$ & $\begin{array}{c}\text { Median } \\
\text { Z-axis } \\
\text { Deviation* } \\
\text { [mm] }\end{array}$ & $\begin{array}{c}\text { Median } \\
\text { Total } \\
\text { Deviation } \\
\text { [mm] }\end{array}$ \\
\hline 0.08 & 0.07 & 0.01 & 0.77 \\
\hline
\end{tabular}

* Absolute value of deviation

\subsection{PLANE SPAN AND MATRIX RESOLUTION}

In order to extract a series of cross-sections from the point cloud, the width of the projection band and the number of cross-section planes were determined. The width of the projection band defines the subspace from which points are projected onto the surface of the cross-sectional plane (Fig. 4). The number of cross-sectional planes is determined by the coverage parameter. Coverage indicates what percentage of points from the cloud are contained within the projection areas. The number of planes of a section is determined from the following formula: 


$$
n=\left[\frac{\left(z_{\max }-z_{\min }\right) \cdot p}{b \cdot 100 \%}\right]
$$

where: $z_{\max }$ - furthest point in $Z$ axis, $z \min$ - closest point in the $Z$ axis, $p$ - coverage [\%], $b$ - width of the projection band [mm].

The span vector of the cross-sectional planes has the following form:

$$
z=\left[z_{1}, z_{2}, z_{3}, \ldots, z_{n-1}, z_{n}\right]
$$

where:

$$
\begin{gathered}
z_{i+1}=z_{i}+\Delta z \\
\Delta z=\frac{z_{\max }-z_{\min }}{n-1}
\end{gathered}
$$

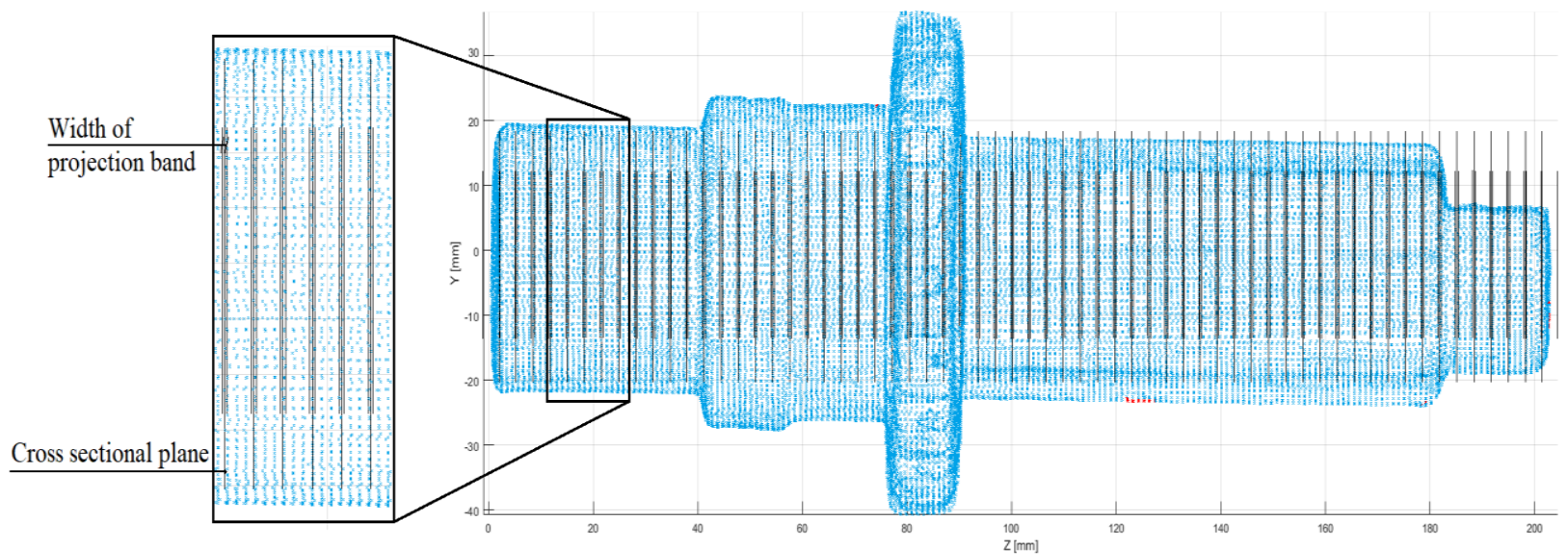

Fig. 4. Vector of section planes with marked projection areas

A matrix was applied to the resulting cross-sections. The typical shaft manufacturing technology is turning, so the base geometry of the part is a rotating solid. The band most frequently activated is therefore the ring (Fig. 5a). The resolution of the matrix is chosen based on the solution of Gauss's Circle Problem (5) [20]:

$$
N(r)=1+4 \cdot \sum_{i=1}^{\infty}\left(\left\lfloor\frac{(r)^{2}}{4 i+1}\right\rfloor-\left\lfloor\frac{(r)^{2}}{4 i+3}\right\rfloor\right)
$$

where: $N(r)$ - number of points with integer coordinates inside a circle of radius $r, r$ - radius of the circle embedded in the Cartesian coordinate system.

From the interpretation of Gauss's Circle Problem it follows that the number of active pixels in an $\mathrm{n} \times \mathrm{n}$ matrix superimposed on a circle is described by equation (6). The activation bandwidth is $12.5 \%$ of resolution. The band of active pixels together with the active nodes is shown in Fig. 5 b. 
a)

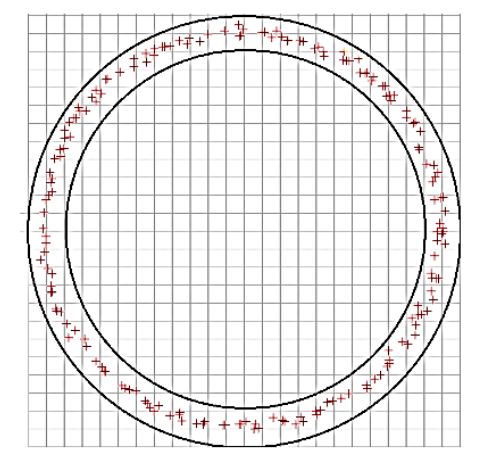

b)

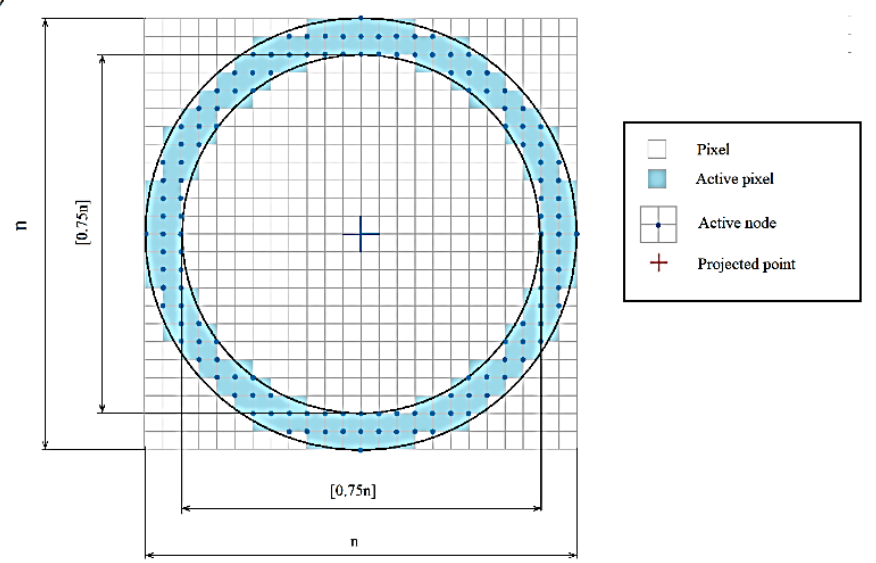

Fig. 5. Projected points on the activation area

$$
\begin{gathered}
A=1+4 \cdot \sum_{i=1}^{\infty}\left(\left\lfloor\frac{\left(\frac{n}{2}\right)^{2}}{4 i+1}\right\rfloor-\left\lfloor\frac{\left(\frac{n}{2}\right)^{2}}{4 i+3}\right\rfloor\right) \\
-\left(1+4 \cdot \sum_{i=1}^{\infty}\left(\left\lfloor\frac{\left(\frac{n-0.25 n}{2}\right)^{2}}{4 i+1}\right\rfloor-\left\lfloor\frac{\left(\frac{n-0.25 n}{2}\right)^{2}}{4 i+3}\right\rfloor\right)\right)
\end{gathered}
$$

Where: $A$ - number of pixels in the projection band, $n^{2}$ - resolution of the superimposed matrix.

The number of active pixels should be approximately three times the number of points in the projection band. This number guarantees a high probability of completely filling the pixels in the projection band. After transformation of equation (6) and simplification, the following is obtained:

$$
L=12 \cdot \sum_{i=1}^{\infty}\left(\left\lfloor\frac{\left(\frac{n}{2}\right)^{2}}{4 i+1}\right\rfloor-\left\lfloor\frac{\left(\frac{n}{2}\right)^{2}}{4 i+3}\right\rfloor-\left(\left\lfloor\frac{\left(\frac{3 n}{8}\right)^{2}}{4 i+1}\right\rfloor-\left\lfloor\frac{\left(\frac{3 n}{8}\right)^{2}}{4 i+3}\right\rfloor\right)\right)
$$

where: $L$ - mean number of points in the cross-section, $n^{2}$ - matrix resolution.

For an average of 360 points, the chosen resolution is $50 \times 50$. Within each pixel, points were counted and saved in an "M" matrix. The "M" matrix values were then scaled to $<0.255>(8)$ :

$$
\bigwedge_{\substack{m, n \in<0,50>\\ m, n \in N}} M^{\prime}(m, n)=\operatorname{round}\left(\frac{255 \cdot M(m, n)}{\max (M)}\right)
$$


where: $M$ - matrix of the number of points within each pixel, $M$ ' - matrix $M$ with values scaled to .jpg format, $\max (M)$ - the maximum value occurring in the matrix $M$.

The chosen resolution is high enough to preserve the shape of the section, while being low enough to preserve the continuity of the outline (Fig. 6b). Using a lower resolution results in a loss of section shape information (Fig. 6a), while too high a resolution results in a break in contour continuity (Fig. 6c). Matlab's toolbox, Boundary Tracing in Images, was used as an indicator of contour continuity.

The $M$ matrix thus prepared was converted to single channel grayscale JPG format. The files created in this way were labelled as belonging to one of the five types of shaft degrees.

a)

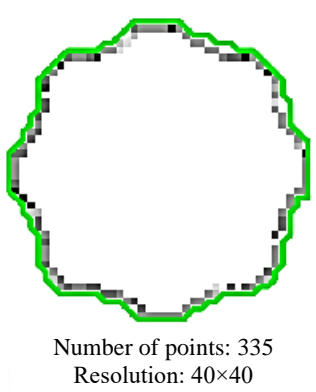

b)

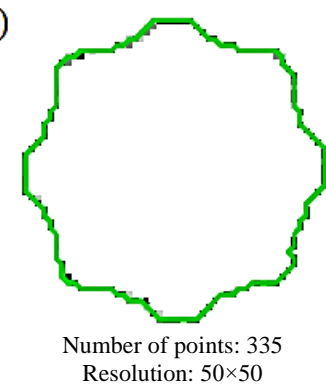

c)

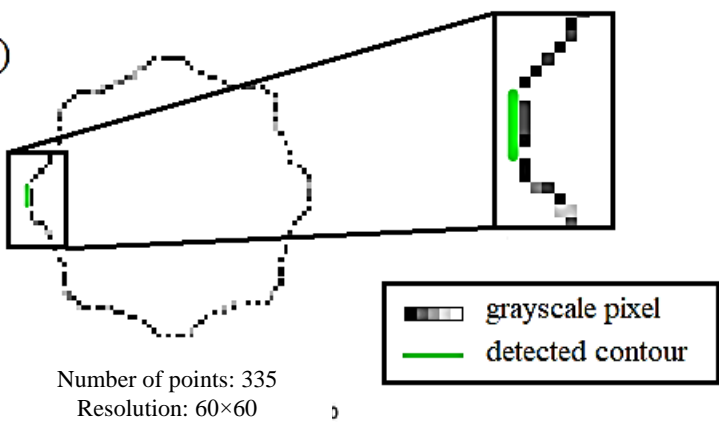

Fig. 6. Influence of the resolution on contour continuity

\subsection{CROSS-SECTION ORIENTATION}

The cross-section images were then rotated to the expected position. The expected positions for the spline, groove and milled step are shown in Fig. 7.

a)

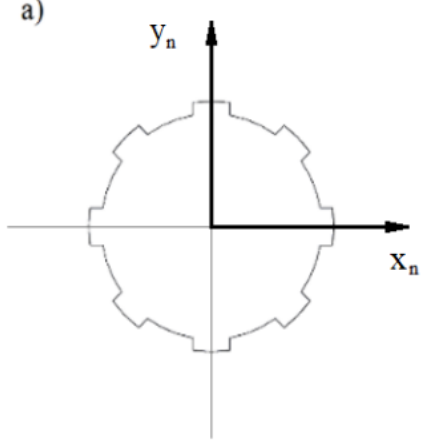

b)

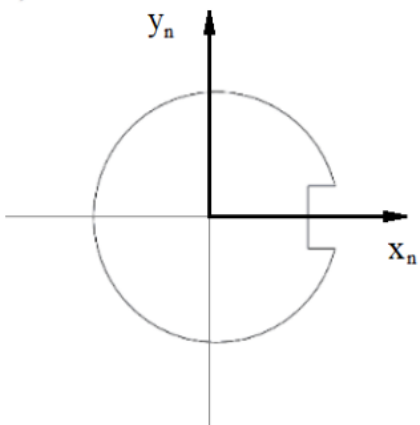

c)

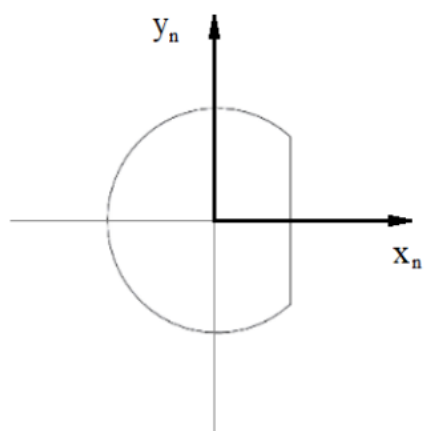

Fig. 7. Expected position of: a) spline; b) groove; c) milled step

The correction value was determined using a convolutional neural network for regression. The image format was used, therefore convolutional neural network could be applied [21]. A network architecture with four convolutional layers was used (Fig. 8). The cross-sections were brought to the expected position with an accuracy of $2^{\circ}$. 


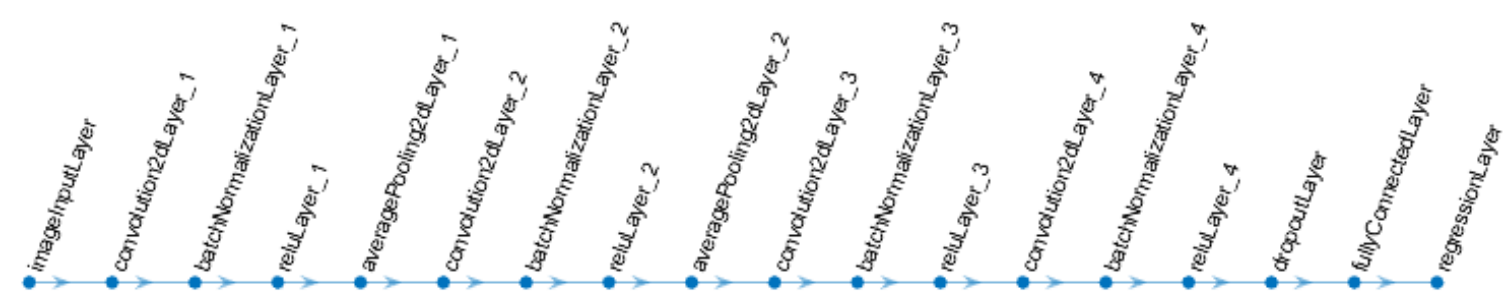

Fig. 8. Architecture of a convolutional neural network for regression

The network was built and learned in Matlab R2020b using the Deep Learning Toolbox. To collect data for learning, 35 cross-sections with each label were randomly selected. Each cross-section was manually brought to the expected position. The database thus collected was then extended by introducing controlled rotation in $180^{\circ}$ and $2^{\circ}$ steps. Every operation on the image was carried out on a temporary copy of the image. The original file after manual correction was further transformed. In this way, a database of 3150 images for each label was collected.

The result of a convolutional neural network for regression is a rotation value $\theta$. Each cross-section was rotated by the designated correction value and then scaled to $50 \times 50$ resolution. The rotation is performed by means of a homogeneous transformation on the section plane in the local section coordinate system (2) (Fig. 9).

$$
\left[\begin{array}{cccc}
x^{\prime}{ }_{1} & x^{\prime}{ }_{2} & \ldots & x_{n}^{\prime} \\
y^{\prime}{ }_{1} & y^{\prime}{ }_{2} & \ldots & y^{\prime}{ }_{n} \\
1 & 1 & \ldots & 1
\end{array}\right]=\left[\begin{array}{ccc}
\cos \theta & -\sin \theta & 0 \\
\sin \theta & \cos \theta & 0 \\
0 & 0 & 1
\end{array}\right]\left[\begin{array}{cccc}
x_{1} & x_{2} & \ldots & x_{n} \\
y_{1} & y_{2} & \ldots & y_{n} \\
1 & 1 & \ldots & 1
\end{array}\right]
$$
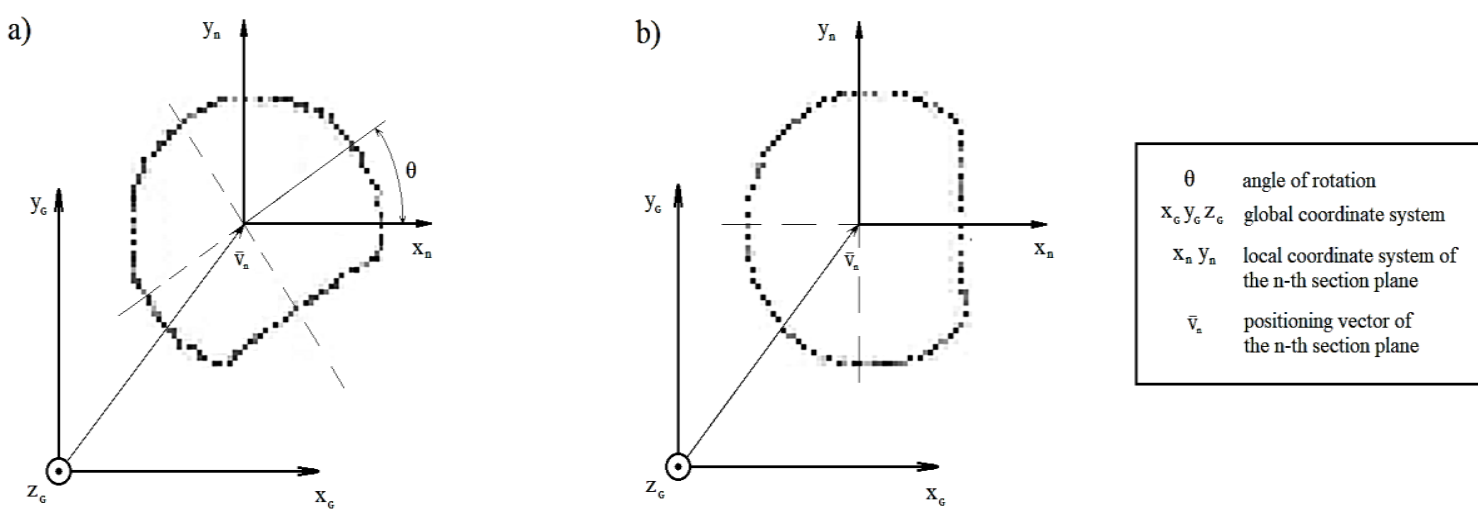

Fig. 9. Correction of the cross-section position

\subsection{CROSS-SECTION IDENTIFICATION}

A proper convolutional neural network for identification consists of a single convolutional layer. The network architecture for identification is shown in Fig. 10. The use of such a simplified network was made possible by bringing the cross-section to the expected position. 


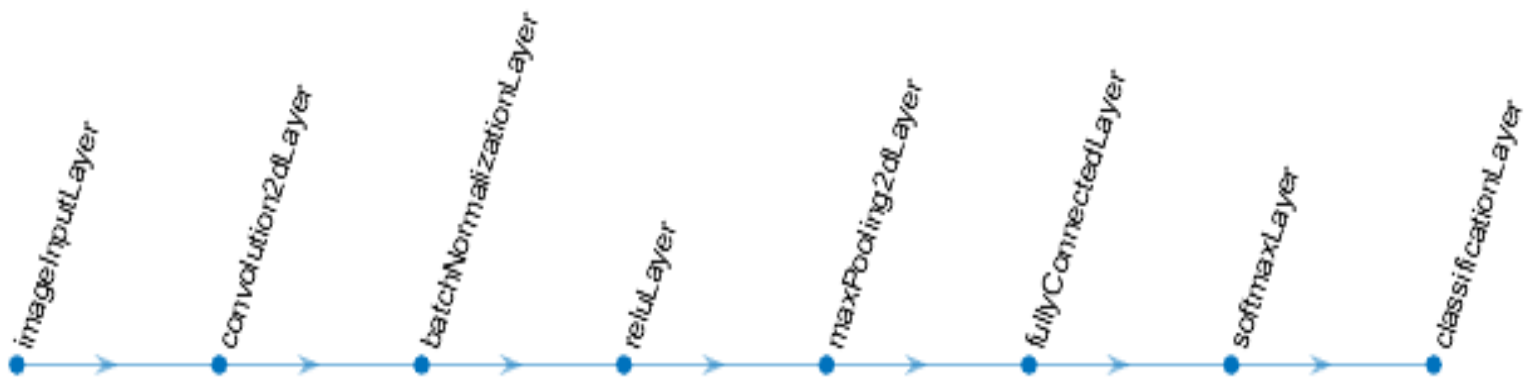

Fig.10. Architecture of a convolutional neural network for identification

Data for the study were collected as described in the previous sections. A total of 6137 cross-sectional images were collected in five label types (Table 1). The data were randomly divided into three parts: data for learning the neural network, data for validating the neural network and data for testing the neural network. Data for learning accounted for $90 \%$ of all images collected, data for validation and data for testing 5\% each. In addition, 195 crosssections were obtained from the test shaft. The test shaft contained each of the five types of degrees recognized.

Table 1. Number of images in each label for machine learning

\begin{tabular}{|l|c|}
\hline Label & Count \\
\hline gear & 1786 \\
\hline groove & 576 \\
\hline milled Step & 1026 \\
\hline simple Step & 972 \\
\hline spline & 1777 \\
\hline
\end{tabular}

Once the data was collected and the neural network architecture was created, the learning process was carried out. The network was taught using the Stochastic Gradient Descent with Momentum method. Due to the large amount of data in a small number of classes, it was decided to close the learning process within a period of one epoch [22]. The size of a single batch of data for learning (mini-batch) was set at 16 images. The best results were obtained for the Initial Learning Rate parameter at 0.0005 . During the learning process the network was validated every 10 iterations.

The performance of the neural network was then tested using a test image database. Images were classified using a neural network and then the original labels were extracted from the test database. The results were collated together as a confusion chart (Fig. 11).

The accuracy of the network performance was calculated:

$$
\operatorname{acc}=\frac{c}{n} \cdot 100 \%
$$

where: $c$ - number of correctly classified images, $n$ - number of all tested images. So:

$$
a c c=100 \%
$$


In addition, a filter taking into account the probability of identification was applied. Results with confidence scores below $90 \%$ were discarded:

$$
\operatorname{acc}_{90}=\frac{c_{90}}{n} \cdot 100 \%
$$

where: $C_{90}$ - number of classified images with confidence score above $90 \%, n$ - number of all tested images. So:

$$
\operatorname{acc}_{90}=99.35 \%
$$

In addition, mean confidence score for identifications were determined:

$$
p_{a v}=\frac{\sum p_{i}}{n}
$$

where: $p_{i}$ - maximum prediction probability of the $i$-th cross-section, $n$-number of all tested images. Therefore:

$$
p_{a v}=99.75 \% \text {. }
$$

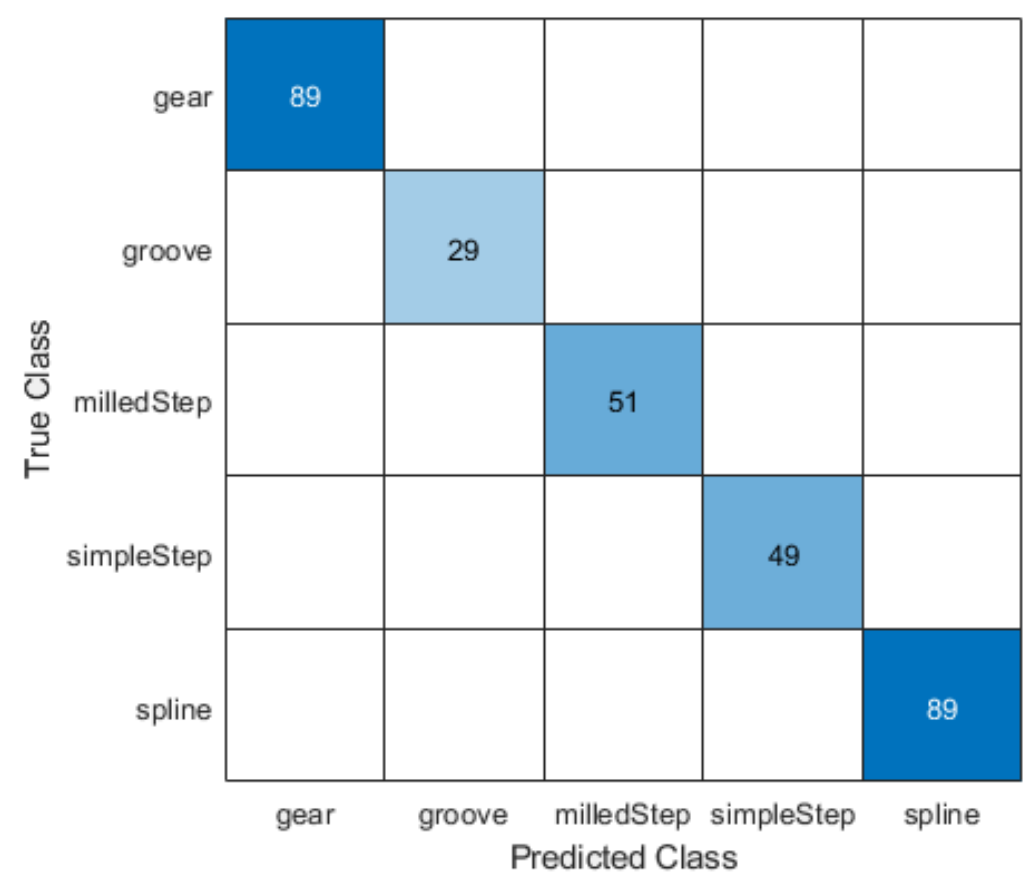

Fig. 11. Confusion chart of the convolutional neural network

To test the performance of the recognition method, the geometric properties of the scan and the original CAD file were identified. The convergence of the two point clouds is described in section 2.1. The result of the identification algorithms on the reference geometry is shown in Fig. 12a. The result of the identification algorithms on the geometry acquired by scanning is shown in Fig. 12b. 
a)

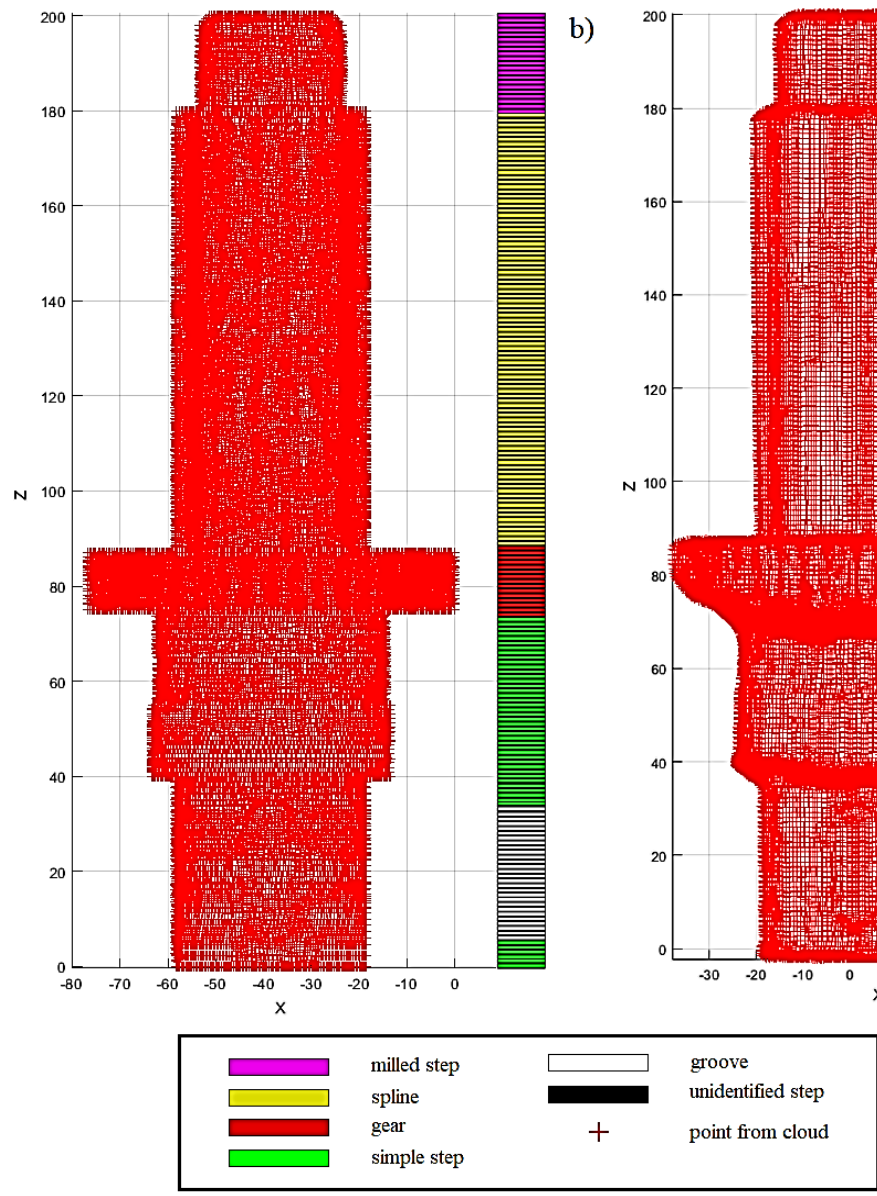

Fig. 12. a) Reference results - based on CAD model identification, b) Method result - based on scan identification

\subsection{DETERMINATION OF DIMENSIONS}

Based on the predictions made, the overall dimensions of the cross-sections were determined. In order to be as accurate as possible, the dimensions were determined on the basis of cross-sections created by projecting points on the cross-section plane (Fig. 13). In the case of the spline and groove, contours from the type series (according to PN-ISO 14:1664 and PN-70/M-85005) were adjusted and the degree of adjustment to the cross-section points was checked [23]. The coordinates of the centers $\left(x_{i}, y_{i}\right)$ were determined from the adjusted contours.

It should be noted that for shaft steps interfacing with other machine parts in tolerances higher than IT14 according to PN-EN ISO 286-1:2011 and for gears it is necessary to specify the exact dimensions manually.

Cross-sections with a defined class membership and a fixed dimension were grouped into shaft steps. A shaft step is considered to be at least four consecutive shaft sections belonging to the same type of step with a difference of dimensions describing the contour not exceeding IT14 tolerance. The grouping areas were then extended so that continuity of steps was maintained. The cross sections grouped into shaft steps are shown in Fig. 14. 

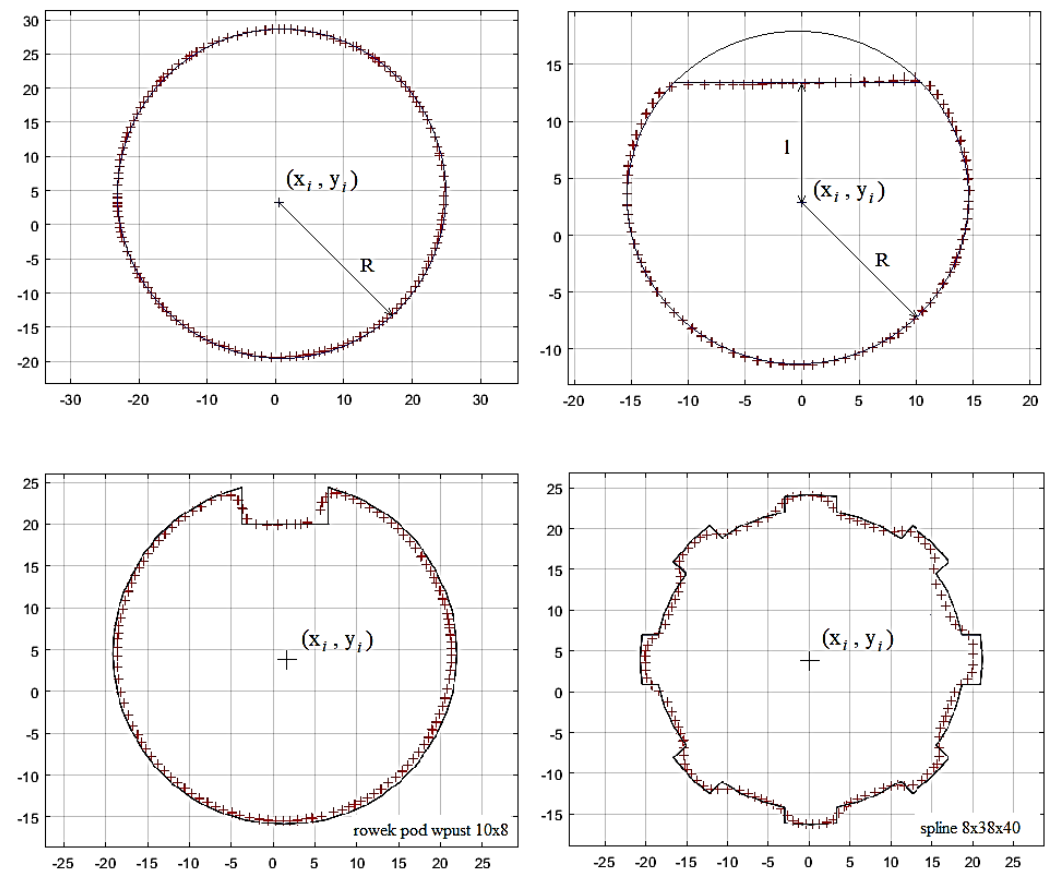

Fig. 13. Determination of dimension from projected points in the cross-section plane
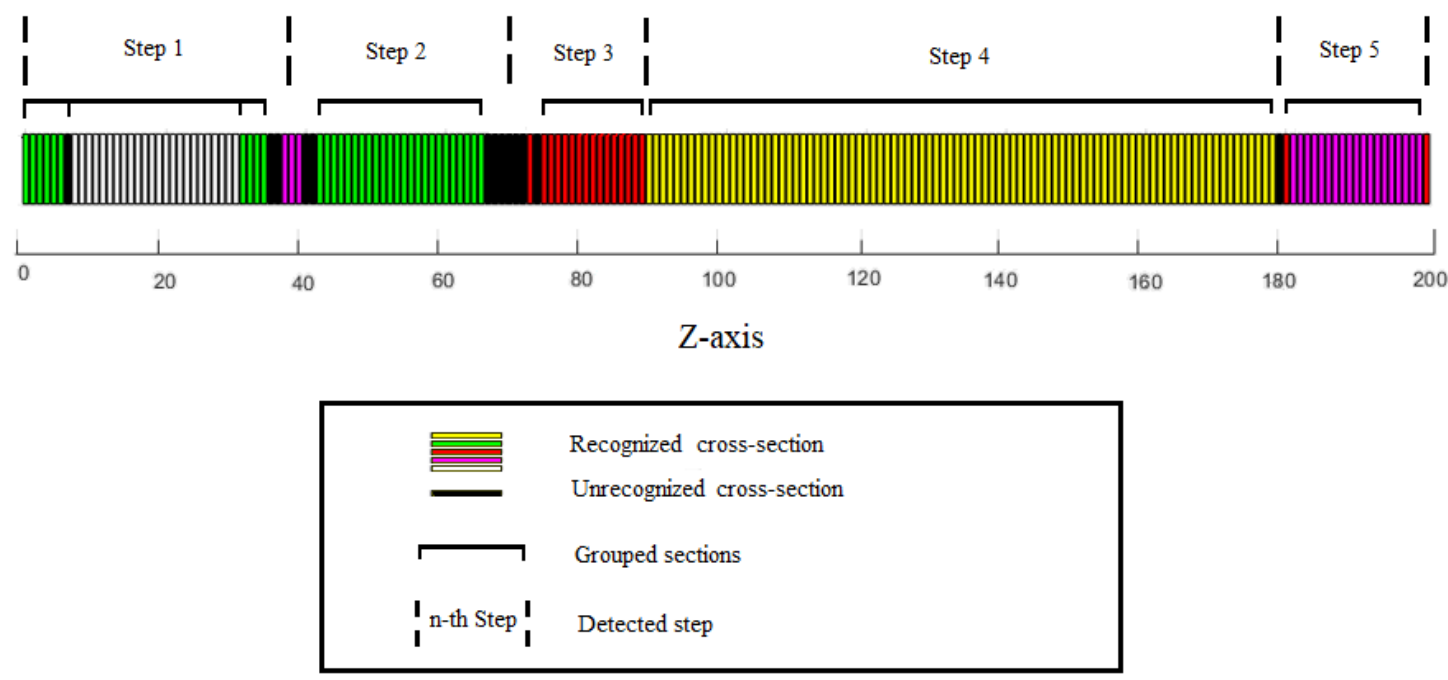

Fig. 14. Assignment of a cross-section to a step

\subsection{DETERMINATION OF SHAFT AXIS}

Based on the identified coordinates of the center points, the axis of the shaft was adjusted using the least squares method. The adjustment was performed in the $X Z$ and $Y Z$ planes (Fig. 15), where:

$X$ - vector of x-coordinates of the cross-section centers in the global system, $Y$ - vector of y-coordinates of the cross-section centers in the global system, $Z$ - vector of z-coordinates of the cross-section centers in the global system, 
$\bar{X}$ - mean value of vector $X$,

$\bar{Y}$ - the mean value of vector $Y$,

$\bar{Z}$ - the mean value of vector $Z$,

$n$ - number of points.

The directional coefficients $a_{X Z}$ and $a_{Y Z}$ were determined from the following formulae:

$$
\begin{aligned}
a_{X Z} & =\frac{\sum(Z \cdot X)-n \cdot \bar{Z} \cdot \bar{X}}{\sum Z^{2}-n \cdot \bar{Z}^{2}} \\
a_{Y Z} & =\frac{\sum(Z \cdot Y)-n \cdot \bar{Z} \cdot \bar{Y}}{\sum Z^{2}-n \cdot Z^{2}}
\end{aligned}
$$

Coefficients $b_{X Z}$ and $b_{Y Z}$ were determined from the equation:

$$
\begin{aligned}
& b_{X Z}=\bar{X}-a_{X Z} \cdot \bar{Z} \\
& b_{Y Z}=\bar{X}-a_{Y Z} \cdot \bar{Z}
\end{aligned}
$$

The equation of the axis in the global coordinate system has the following form:

$$
\left[\begin{array}{l}
x \\
y
\end{array}\right]=\left[\begin{array}{cc}
a_{X Z} & 1 \\
1 & a_{Y Z}
\end{array}\right] \cdot\left[\begin{array}{l}
Z \\
Z
\end{array}\right]+\left[\begin{array}{l}
b_{X Z} \\
b_{Y Z}
\end{array}\right]
$$

The whole model was corrected by rotation and translation so that the corrected axis was parallel to the $Z$ axis in the $X Z$ and $X Y$ planes. The adjustment of the axes in the indicated planes is shown in Fig. 15.
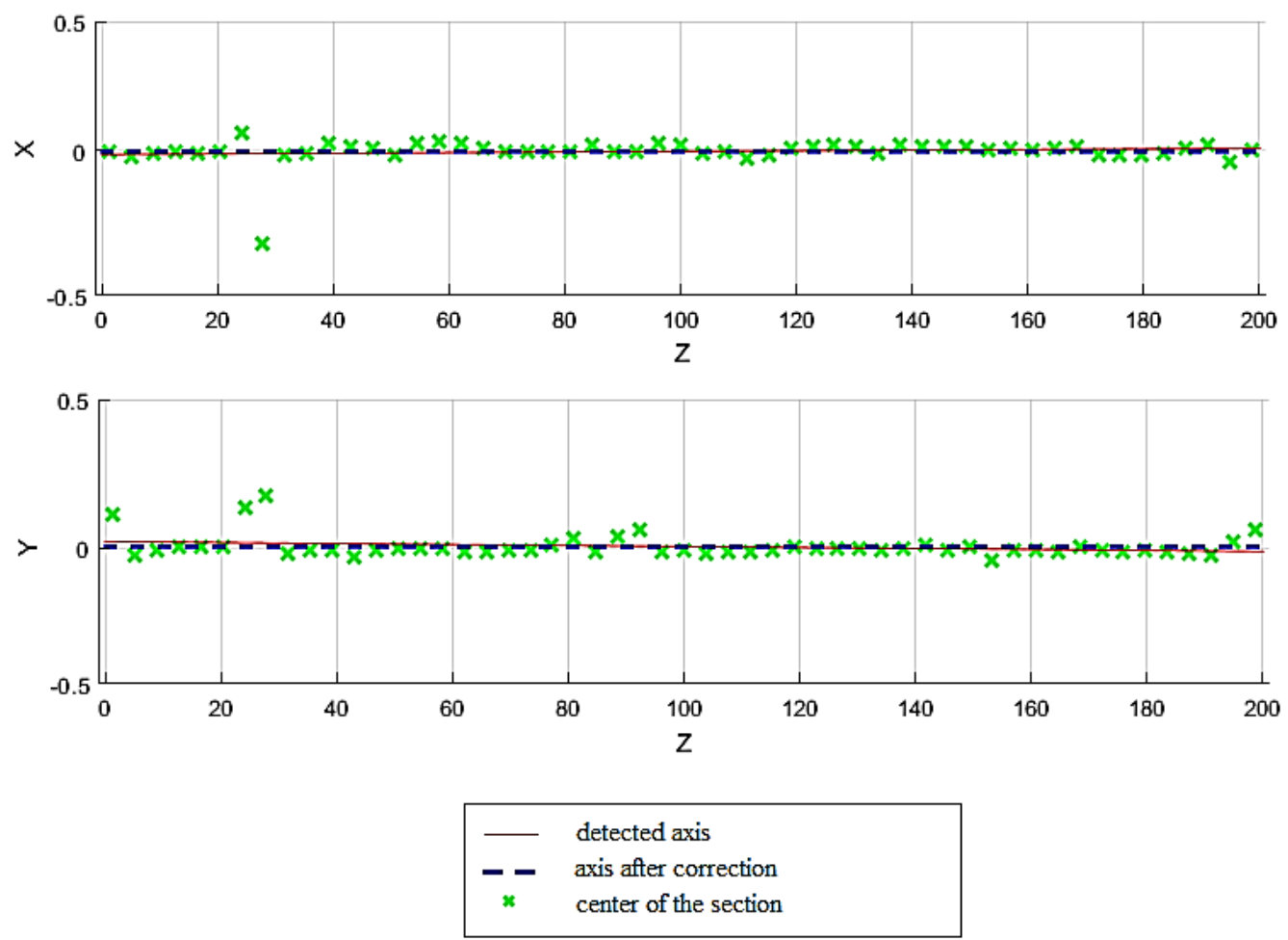

Fig. 15. Adjustment and correction of shaft axes in the $X Z$ and $Y Z$ planes in the global coordinate system 
The model was reconstructed in SolidWorks and a functional feature tree was created [24]. First, a base geometry was created. The axial section plane of the shaft and the shaft axis were created basing on recognized $X$ - and $Z$-axis dimensions. An axial section sketch was created on the $X Z$ plane (Top plane) and then a base solid was created using the "Revolved Boss/Base" function. The first automatically generated operation in the feature tree corresponds to a turning operation. The "Extruded Cut" function was then used to create a groove, a spline, a gear and also a milled step cut. Contours for following features were automatically created on generated planes which are parallel to a $X Y$ plane (Front plane). These operations correspond to the subsequent technological milling operations. The geometry reconstruction process was automated by a script. Automation of the shaft recreation process was possible by identification diameters in the corresponding axes. Reconstructing the model using the program's functions allows for the creation of a feature tree. The geometry reconstructed from the scan is shown in Fig. 16b, while the geometry reconstructed from the reference geometry is shown in Fig. 16c.

a)

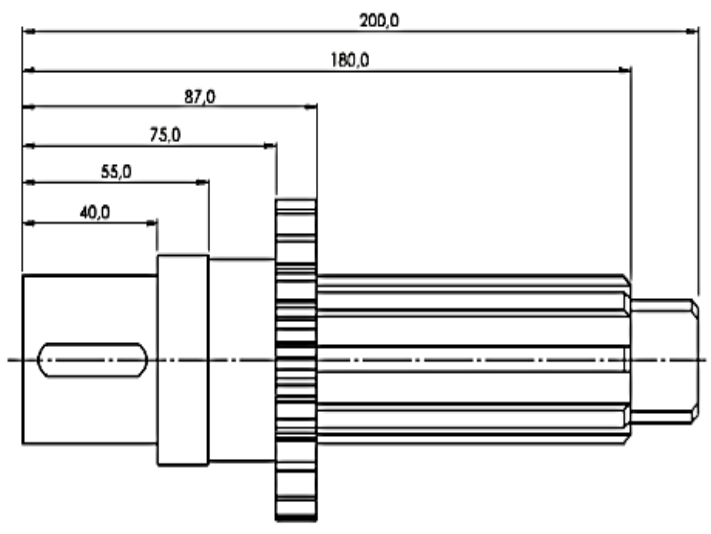

b)

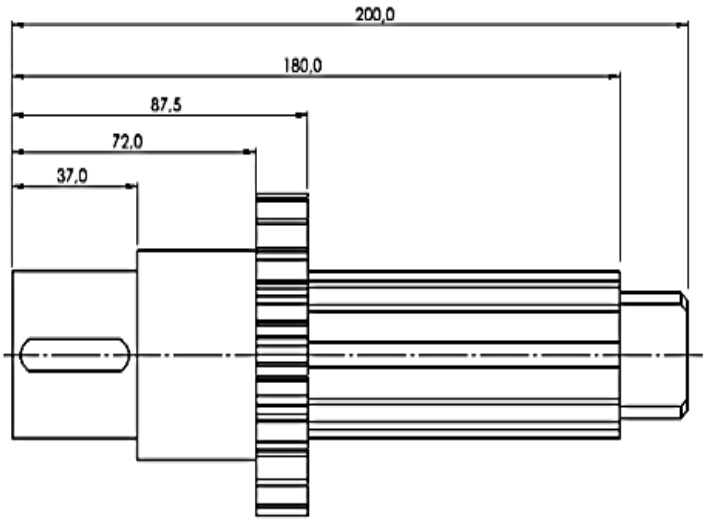

c)

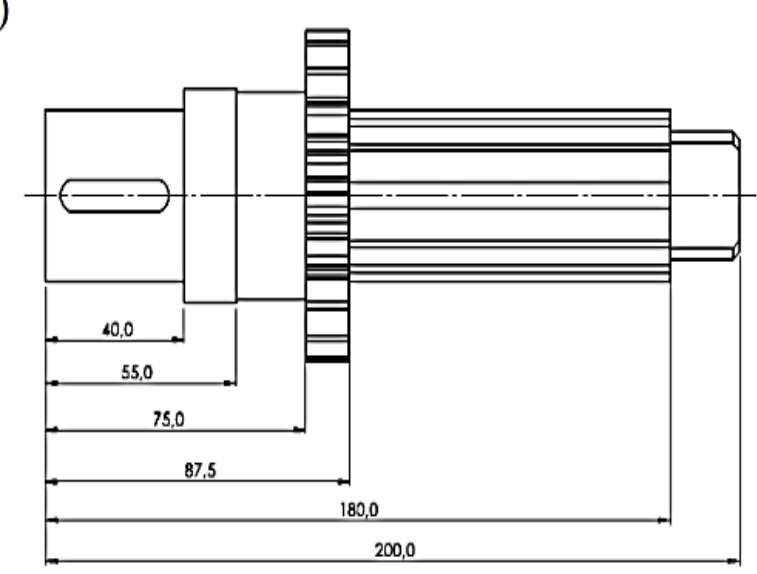

Fig. 16. a) Reference geometry; b) Geometry reconstructed from the scan; c) Geometry reconstructed directly from reference geometry 
The largest dimensional differences (Fig. 16b) are seen where the quality of the scan decreases. Discrepancies of up to $3 \mathrm{~mm}$ have arisen at the gear. The quality of the scan is described in section 2.1 and shown in Fig. 3. In the model reconstructed from the scan, the disappearance of one step and the chamfering of one of the steps can be observed. The variability of the undetected features is less than the accepted IT14 tolerance.

\section{RESULTS}

The method and operation of the system was evaluated and the identification system was verified. How the algorithms and method were evaluated and verified is shown in Fig. 17.
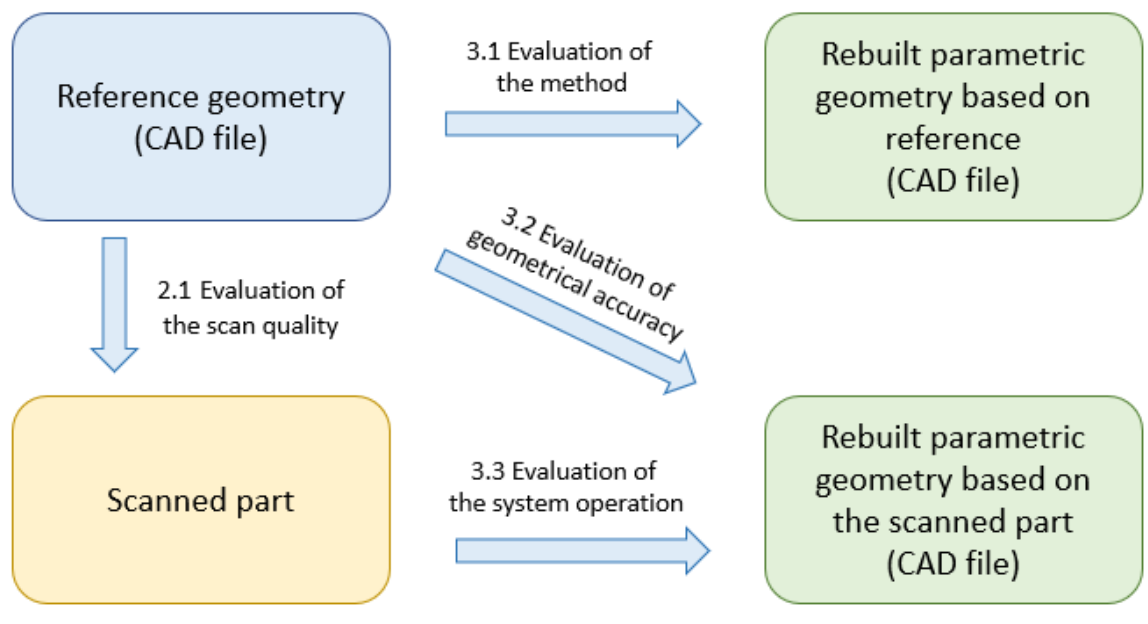

Fig. 17. Evaluation and verification of the method and algorithms

\subsection{EVALUATION OF THE METHOD}

The performance of the algorithms for identification and reconstruction of parametric geometry was evaluated by a comparative analysis of the reconstructed geometry based on the reference with the reference geometry. The distribution of deviations and the histogram of the distribution of deviations are shown in Fig. 18. The standard deviation and median values are summarized in Table 2.

The accuracy of the identification method $a_{c c_{\text {method }}}$ was determined by comparing the identified cross-sections (Fig. 12b) to the prediction of the reference shaft (Fig. 12a). Incorrectly identified sections and those with a confidence score below $90 \%$ were counted.

The accuracy of the identification method was calculated from the formula:

$$
a c c_{\text {method }}=\frac{c_{\text {mis }}+c_{90}}{n} \cdot 100 \%
$$


where: $c_{\text {mis }}$ - number of cross-sections wrongly identified, $c_{90}$ - number of cross-sections identified with a confidence score less than $90 \%, n$ - number of all cross-sections.

Therefore:

$$
a c c_{\text {method }}=86.57 \%
$$

Table 2. Standard deviation and median value of deviation

\begin{tabular}{|c|c|c|c|}
\hline $\begin{array}{c}\text { Standard } \\
\text { deviation } \\
\text { X-axis }\end{array}$ & $\begin{array}{c}\text { Standard } \\
\text { deviation } \\
\text { Y-axis }\end{array}$ & $\begin{array}{c}\text { Standard } \\
\text { deviation } \\
\text { Z-axis }\end{array}$ & $\begin{array}{c}\text { Total } \\
\text { Standard } \\
\text { deviation }\end{array}$ \\
\hline 0.08 & 0.08 & 0.35 & 0.36 \\
\hline $\begin{array}{c}\text { Median } \\
\text { X-axis } \\
\begin{array}{c}\text { Deviation* } \\
\text { [mm] }\end{array}\end{array}$ & $\begin{array}{c}\text { Median } \\
\text { Y-axis } \\
\text { Deviation* } \\
\text { [mm] }\end{array}$ & $\begin{array}{c}\text { Median } \\
\text { Z-axis } \\
\text { Deviation* } \\
\text { [mm] }\end{array}$ & $\begin{array}{c}\text { Median } \\
\text { Total } \\
\text { Deviation } \\
\text { [mm] }\end{array}$ \\
\hline 0.01 & 0.01 & 0.02 & 0.02 \\
\hline
\end{tabular}

${ }^{*}$ Absolute value of deviation

a)

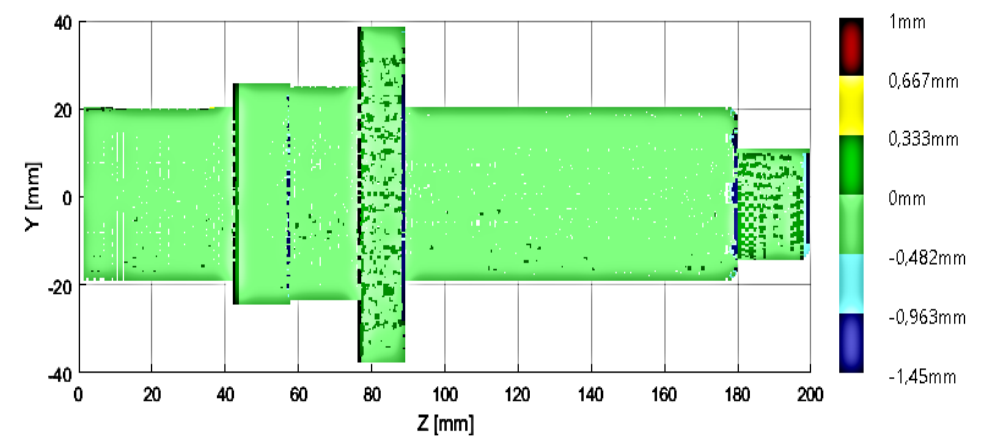

b)

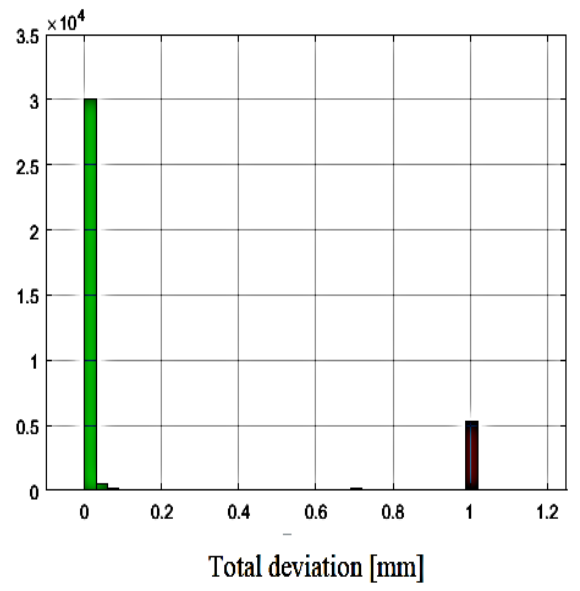

Fig. 18. a) Values of deviation of comparison rebuilt geometry based on reference with reference geometry, b) Distribution histogram

\subsection{EVALUATION OF GEOMETRICAL ACCURACY}

Geometrical accuracy was assessed by comparative analysis of the reconstructed geometry from the scan with the reference geometry. The differences between the reconstructed geometry and the reference geometry are due to the displacement of the opening and closing planes of the shaft steps, the displacement of the gear and the disappearance of one of the steps with a pitch below the specified tolerance. The standard deviation and median deviation are shown in Table 3. The deviation values and the histogram of the distribution are shown in Fig. 19. 
Table 3. Standard deviation and median value of deviation

\begin{tabular}{|c|c|c|c|}
\hline $\begin{array}{c}\text { Standard } \\
\text { deviation } \\
X \text {-axis }\end{array}$ & $\begin{array}{c}\text { Standard } \\
\text { deviation } \\
Y \text {-axis }\end{array}$ & $\begin{array}{c}\text { Standard } \\
\text { deviation } \\
\text { Z-axis }\end{array}$ & $\begin{array}{c}\text { Total } \\
\text { Standard } \\
\text { deviation }\end{array}$ \\
\hline 0.36 & 0.33 & 0.57 & 0.54 \\
\hline $\begin{array}{c}\text { Median } \\
X \text {-axis } \\
\text { Deviation } \\
\text { [mm] }\end{array}$ & $\begin{array}{c}\text { Median } \\
\text {-axis } \\
\text { Deviation* } \\
\text { [mm] }\end{array}$ & $\begin{array}{c}\text { Median } \\
\text { Z-axis } \\
\text { Deviation* } \\
\text { [mm] }\end{array}$ & $\begin{array}{c}\text { Median } \\
\text { Total } \\
\text { Deviation } \\
\text { [mm] }\end{array}$ \\
\hline 0.05 & 0.05 & 0.01 & 0.10 \\
\hline
\end{tabular}

${ }^{*}$ Absolute value of deviation

a)

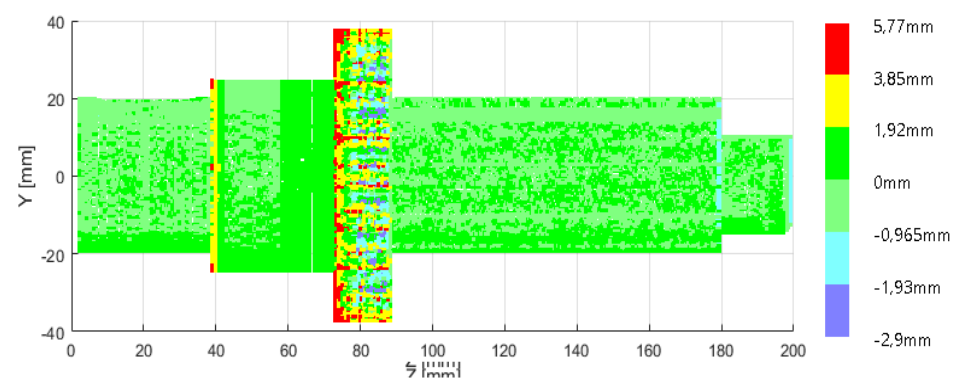

b)

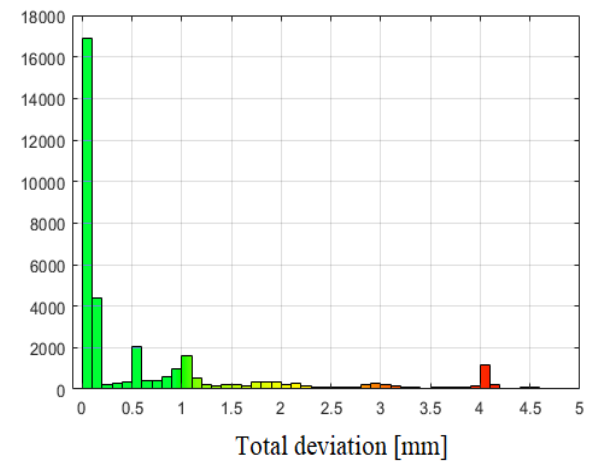

Fig. 19. a) Values of deviation of comparison rebuilt geometry based on scan with reference geometry b) Distribution histogram

\subsection{EVALUATION OF THE SYSTEM OPERATION}

Evaluation of the operation of the identification system is made by comparative analysis of the geometry reconstructed from the scan with the scan. The standard deviation and median deviation are shown in Table 4. The deviation values and the histogram of the distribution are shown in Fig. 20.

Table 4. Standard deviation and median value of deviation

\begin{tabular}{|c|c|c|c|}
\hline $\begin{array}{c}\text { Standard } \\
\text { deviation } \\
\text { X-axis }\end{array}$ & $\begin{array}{c}\text { Standard } \\
\text { deviation } \\
\text { Y-axis }\end{array}$ & $\begin{array}{c}\text { Standard } \\
\text { deviation } \\
\text { Z-axis }\end{array}$ & $\begin{array}{c}\text { Total } \\
\text { Standard } \\
\text { deviation }\end{array}$ \\
\hline 0.47 & 0.46 & 0.65 & 0.71 \\
\hline Median & $\begin{array}{c}\text { Median } \\
\text { X-axis }\end{array}$ & $\begin{array}{c}\text { Median } \\
\text { Z-axis }\end{array}$ & $\begin{array}{c}\text { Zedian } \\
\text { Total }\end{array}$ \\
$\begin{array}{c}\text { Deviation } \\
\text { Deviation }\end{array}$ & $\begin{array}{c}\text { Deviation* } \\
\text { [mm] }\end{array}$ & $\begin{array}{c}\text { Deviation } \\
\text { [mm] }\end{array}$ \\
\hline 0.13 & 0.13 & 0.02 & 0.36 \\
\hline
\end{tabular}

* Absolute value of deviation 


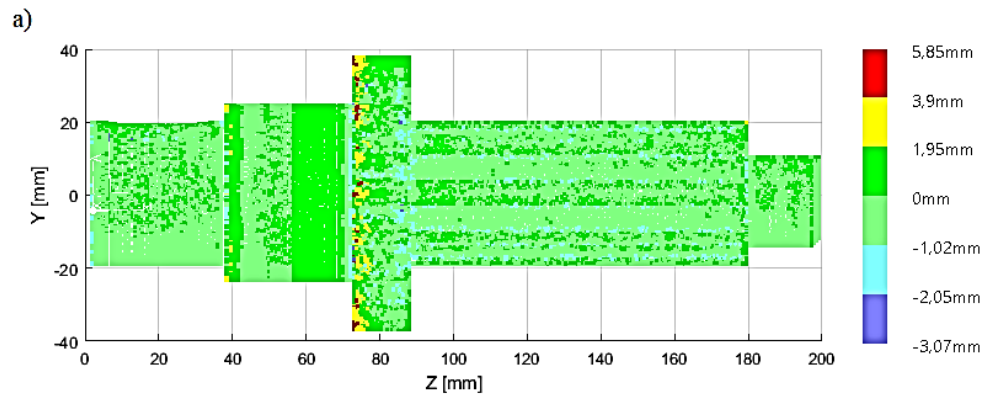

b)

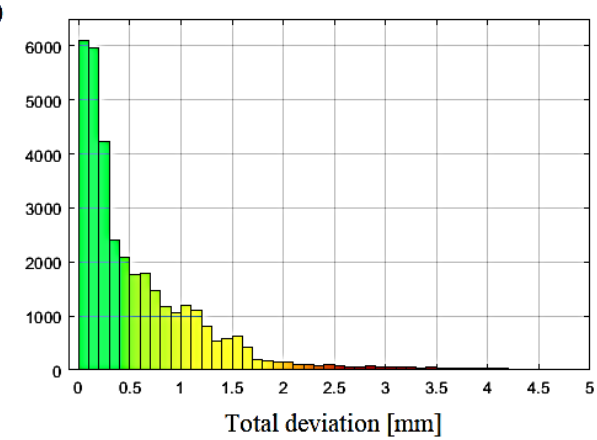

Fig. 20. a) Values of deviation of comparison rebuilt geometry based on scan with scan,

b) Distribution histogram

When determining the accuracy of the identification algorithms themselves, it is assumed that the original geometry is unknown. The accuracy of the identification algorithms operation $a c c_{\text {algorithm }}$ is therefore determined solely by the number of cross-sections identified with a confidence score of less than $90 \%$. The accuracy of the algorithms is determined by the formula:

$$
a c c_{\text {algorithm }}=\frac{c_{90}}{n} \cdot 100 \%
$$

where: $c_{90}$ - number of cross-sections identified with a confidence score less than $90 \%, n-$ number of all cross-sections.

Therefore:

$$
a c c_{\text {algorithm }}=91.04 \% \text {. }
$$

\section{CONCLUSION}

A method for identifying the structural features of a shaft class part from a series of cross-sections is presented. In Industry 4.0, this method can be used to create digital twins of processes in CAPP systems and objects in CAR systems. The method can be used in CAPP systems to classify design features for manufacturing technique selection and in CAR systems to reconstruct parametric geometry from a point cloud. The most important features of the method are listed below.

2D neural networks were used to identify 3D geometric features. Owing to the preparation of cross-sections, shallow networks can be used, which reduces the running time of the program.

$>$ The method presented allows the model to be reproduced with greater dimensional accuracy than the scan alone. This is possible by adjusting the dimension of the identified geometric feature to the dimensional series using dimensional tolerance.

The method presented allows to create a feature tree. Properly created feature tree allows for quick editing of the model and feature parametrization in CAD system. In addition, a properly created feature tree allows the planning of manufacturing technology by ordering subsequent technical operations in CAM programs [25]. 
The method shown is versatile. It can be used in CAPP and CAR systems. The method works for scans of varying density and quality. A method for selecting cross-sectional planes and resolution depending on the point cloud abundance is shown.

However, this method has limitations. The presented algorithms do not reproduce wear of parts larger than tolerance class IT14 according to PN-EN ISO 286-1:2011 and do not reproduce damages and defects. The method is not capable of detecting characteristics with a variability smaller than the selected tolerance. The method was presented on geometric features that are only variable in one axis. The variability of features in one axis is typical of machine parts of the shaft or sleeve class. It is planned to implement presented algorithms as a part of remanufacturing system created at West Pomeranian University of Technology $[26,27]$.

In the future, it is planned to develop the described algorithms and, in particular, to implement algorithms to identify design features of parts of other classes. Future work involves using algorithms to identify variable features in two axes - typical for 2.5D and 3D milling - so the application of the algorithms can be extended to hole, pocket, island, filet or chamfer features recognition, typical of body part classes.

\section{REFERENCES}

[1] BATTY M., 2018, Digital Twins, Environment and Planning B: Urban Analytics and City Sci., 45, 817-820. https://doi.org/10.1177/2399808318796416.

[2] HAAG S., ANDERL R., 2018, Digital Twin - Proof of Concept, Manuf. Lett., 15, 64-66. https://doi.org/ 10.1016/j.mfglet.2018.02.006.

[3] BABIC B., NESIC N., MILJKOVIC Z., 2008, A Review of Automated Feature Recognition with Rule-Based Pattern Recognition, Comput. Ind., 59, 321-337, https://doi.org/10.1016/j.compind.2007.09.001.

[4] ABIODUN O.I., JANTAN A., OMOLARA A.E., DADA K.V., et al., 2019, Comprehensive Review of Artificial Neural Network Applications to Pattern Recognition, IEEE Access, 7, 158820-158846, https://doi.org/10. 1109/ACCESS.2019.2945545.

[5] GHADAI S., BALU A., SARKAR S., KRISHNAMURTHY A., 2018, Learning Localized Features in 3D CAD Models for Manufacturability Analysis of Drilled Holes, Comput. Aided Geom. Des., 62, 263-275. https:// doi.org/10.1016/j.cagd. 2018.03.024.

[6] Han J.H., PRATT M., REGLI WC., 2000, Manufacturing Feature Recognition from Solid Models: a Status Report. IEEE Trans. Robot. Autom., 16, 782-796, https://doi.org/10.1109/70.897789.

[7] SUNIL V.B., PANDE S.S., 2009, Automatic Recognition of Machining Features Using Artificial Neural Networks, Int. J. Adv. Manuf. Technol., 41, 932-947, https://doi.org/10.1007/s00170-008-1536-z.

[8] GONG J-H., ZHANG H., ZHANG G-F., SUN J-G., 2006, Solid Reconstruction Using Recognition of Quadric Surfaces from Orthographic Views, Comput-Aided Des., 38, 821-835, https://doi.org/10.1016/j.cad.2006.04.009.

[9] YE X., LIU H., CHEN L., CHEN Z., PAN X., ZHANG S., 2008, Reverse Innovative Design - an Integrated Product Design Methodology, Comput-Aided Des., 40, 812-827, https://doi.org/10.1016/j.cad.2007.07.006.

[10] WU Z., SONG S., KHOSLA A., FISHER Y., LINGUANG Z., et al. 2015, 3D ShapeNets: A deep representation for volumetric shapes, IEEE Conf. Comput. Vis. Pattern Recognit. CVPR, Boston, MA, USA, IEEE, 1912-1920, https://doi.org/10.1109/CVPR.2015.7298801.

[11] XIA Q., LI S., QIN H., HAO A., 2016, Automatic Extraction of Generic Focal Features on 3D Shapes via Random Forest Regression Analysis of Geodesics-in-Heat, Comput. Aided Geom. Des., 49, 31-43. https://doi.org/ 10.1016/j.cagd.2016.10.003.

[12] ZHANG Z., JAISWAL P., RAI R., 2018, FeatureNet: Machining Feature Recognition Based on 3D Convolution Neural Network, CAD Comput. Aided Des., 101, 12-22, https://doi.org/10.1016/j.cad.2018.03.006.

[13] SHI P., Qi Q., QIN Y., SCOTT P.J., JIANG X., 2020, A Novel Learning-Based Feature Recognition Method Using Multiple Sectional View Representation, J. Intell. Manuf., 31, 1291-1309, https://doi.org/10.1007/s10845-02001533-w. 
[14] BOLOTOV M.A., PECHENIN V.A., RUZANOV N.V., KOLCHINA E.J., 2019, Surface Recognition of Machine Parts Based on the Results of Optical Scanning, Inf. Technol. Nanotechnol, 342-349, https://doi.org/ 10.18287/1613-0073-2019-2391-342-349.

[15] QI C.R., SU H., MO K., GUIBAS L.J., 2017, PointNet: Deep Learning on Point Sets for 3D Classification and Segmentation, Computer Vision Foundation, CVPR, 652-660.

[16] MODABBER A., PETERS F., KNIHA K., GOLOBORODKO E., et al., 2016, Evaluation of the Accuracy of a Mobile and a Stationary System for Three-Dimensional Facial Scanning, J. Cranio-Maxillofac Surg., 44, 17191724, https://doi.org/10.1016/j.jcms.2016.08.008.

[17] CURTIS S.K., HARSTON S.P., MATTSON C.A., 2011, The Fundamentals of Barriers to Reverse Engineering and their Implementation into Mechanical Components, Res. Eng. Des., 22, 245-61, https://doi.org/10.1007/ s00163-011-0109-6.

[18] LEE I.D., SEO J.H., KIM Y.M., CHOI J., HAN S., YOO B., 2020, Automatic Pose Generation for Robotic 3-D Scanning of Mechanical Parts, IEEE Trans. Robot., 36, 1219-1238, https://doi.org/10.1109/TRO.2020.2980161.

[19] BUONAMICI F., CARFAGNI M., FURFERI R., GOVERNI L., LAPINI A., VOLPE Y., 2018, Reverse Engineering of Mechanical Parts: A Template-Based Approach, J. Comput. Des. Eng., 5, 145-159, https://doi.org/ 10.1016/j.jcde.2017.11.009.

[20] LOWRY-DUDA D., 2017, On Some Variants of the Gauss Circle Problem, ArXiv170402376 Math 2017.

[21] ZHANG X., WU F., LI Z., 2021, Application of Convolutional Neural Network to Traditional Data, Expert Syst. Appl., 168, 114185, https://doi.org/10.1016/j.eswa.2020.114185.

[22] KIMURA A., TAKAHASHI I., TANAKA M., YASUDA N., UEDA N., YOSHIDA N., 2017, Single-Epoch Supernova Classification with Deep Convolutional Neural Networks, IEEE 37th Int. Conf. Distrib. Comput. Syst. Workshop ICDCSW, 354-359, https://doi.org/10.1109/ICDCSW.2017.47.

[23] GANDER W., GOLUB G.H., STREBEL R., 1994, Least-Squares Fitting of Circles and Ellipses, BIT Numer. Math., 34, 558-578, https://doi.org/10.1007/BF01934268.

[24] LI N., CHA J., LU Y., 2010, A Parallel Simulated Annealing Algorithm Based on Functional Feature Tree Modeling for 3D Engineering Layout Design, Appl. Soft. Comput., 10, 592-601, https://doi.org/10.1016/j.asoc. 2009.08.033.

[25] TOLOUEI-RAD M., 2006, An Approach Towards Fully Integration, JAMME, 18, September-October.

[26] MIĄDLICKI K., JASIEWICZ M., GOŁASZEWSKI M., KRÓLIKOWSKI M., POWAŁKA B., 2020, Remanufacturing System with Chatter Suppression for CNC Turning, Sensors, 20, 5070, https://doi.org/10.3390/ s20185070.

[27] JASIEWICZ M., MIĄDLICKI K., 2020, An Integrated CNC System for Chatter Suppression in Turning, Adv. Prod. Eng. Manag., 15, 318-330, https://doi.org/10.14743/apem2020.3.368. 